\title{
Prevalence of dementia and major dementia subtypes in Spanish populations: A reanalysis of dementia prevalence surveys, 1990-2008
}

Jesús de Pedro-Cuesta*1, Javier Virués-Ortega ${ }^{1}$, Saturio Vega ${ }^{2}$, Manuel SeijoMartínez ${ }^{3}$, Pedro Saz ${ }^{4}$, Fernanda Rodríguez ${ }^{5}$, Angel Rodríguez-Laso ${ }^{6}$, Ramón Reñé ${ }^{7}$, Susana Pérez de las Heras ${ }^{8}$, Raimundo Mateos ${ }^{9}$, Pablo Martínez-Martín1, José María Manubenss ${ }^{10}$, Ignacio MahilloFernandez ${ }^{1}$, Secundino López-Pousa ${ }^{11}$, Antonio Lobo ${ }^{5}$, Jordi Llinàs Reglà11, Jordi Gascón7, Francisco José García12, Manuel Fernández-Martínez ${ }^{13}$, Raquel Boix ${ }^{1}$, Félix Bermejo-Pareja ${ }^{14}$, Alberto Bergareche ${ }^{15}$, Julián BenitoLeón ${ }^{15,16}$, Ana de Arce ${ }^{17}$ and José Luis del Barrio ${ }^{1}$

Address: ${ }^{1}$ National Centre for Epidemiology, CIBERNED and Alzheimer' Disease Research Unit, Carlos III Institute of Public Health, Madrid, Spain, ${ }^{2}$ Primary Care Administration, Segovia, Spain, ${ }^{3}$ Neurology Unit, Salnés Hospital, Pontevedra, Spain, ${ }^{4}$ Department of Medicine and Psychiatry, Zaragoza University, Zaragoza, Spain, ${ }^{5}$ Neurology Unit, Segovia Hospital, Segovia, Spain, ${ }^{6}$ Madrid Regional Health Authority, Madrid, Spain, ${ }^{7}$ Dementia Diagnosis and Treatment Unit, Neurology Department, Bellvitge University Teaching, Spain, ${ }^{8}$ Llodio Health Center, Day Medical Center, Oroityu-Getxo-Vizcaya, Spain, ${ }^{9}$ Psychiatry Department, University of Santiago de Compostela, Spain, ${ }^{10}$ Neurology Unit, Virgen del Camino Hospital, Pamplona, Spain, ${ }^{11}$ Dementia Unit. Hospital Santa Caterina, Institut d'Assistència Sanitària, Salt, Spain, ${ }^{12 B a r c e l o n a}$ Hospital, Barcelona, Spain, ${ }^{13}$ Geriatrics Unit. Virgen del Valle Geriatric Hospital., Toledo, Spain, ${ }^{14}$ Neurology Service, Cruces Hospital, Day Medical Center, Oroityu-Getxo-Vizcaya, Spain, ${ }^{15}$ Neurology Department, 12 de Octubre University Teaching Hospital, Madrid, Spain, ${ }^{16}$ Centro de Investigación Biomédica en Red sobre Enfermedades Neurodegenerativas (CIBERNED), Madrid, Spain and ${ }^{17}$ Neurology Department, BidasoaHondarribia Hospital, Guipúzcoa, Spain

Email: Jesús de Pedro-Cuesta* - jpedro@isciii.es; Javier Virués-Ortega - jvirues@isciii.es; Saturio Vega - svegaq@semg.es; Manuel SeijoMartínez - mseijom@meditex.es; Pedro Saz - psaz@unizar.es; Fernanda Rodríguez - mfernanda_rodriguez@yahoo.es; Angel RodríguezLaso - angel.rodriguez@salud.madrid.org; Ramón Reñé - rrene@csub.scs.es; Susana Pérez de las Heras - spheras@oroitu.com; Raimundo Mateos - mrmateos@usc.es; Pablo Martínez-Martín - pmartinez@isciii.es; José María Manubens - jmanubens@isciii.es; Ignacio Mahillo-Fernandez - imahillo@isciii.es; Secundino López-Pousa - uvamid@ias.scs.es; Antonio Lobo - loboa@hcu-lblesa.es; Jordi Llinàs Reglà - uvamid@ias.scs.es; Jordi Gascón - jordigneuro@csub.scs.es; Francisco José García - FRANJOGARCIA@telefonica.net; Manuel Fernández-Martínez - mfernandezm@meditex.es; Raquel Boix - rboix@isciii.es; Félix Bermejo-Pareja - fbermejop@meditex.es; Alberto Bergareche - abergaretxe@hbid.osakidetza.net; Julián Benito-León - jbenitol@meditex.es; Ana de Arce - med002273@saludalia.com; José Luis del Barrio - jose.delbarrio@urjc.es

* Corresponding author

Published: 19 October 2009

BMC Neurology 2009, 9:55 doi:10.1 I86/147|-2377-9-55
Received: 27 April 2009

Accepted: 19 October 2009

This article is available from: http://www.biomedcentral.com/I47/-2377/9/55

(C) 2009 de Pedro-Cuesta et al; licensee BioMed Central Ltd.

This is an Open Access article distributed under the terms of the Creative Commons Attribution License (http://creativecommons.org/licenses/by/2.0), which permits unrestricted use, distribution, and reproduction in any medium, provided the original work is properly cited.

\footnotetext{
Abstract

Background: This study describes the prevalence of dementia and major dementia subtypes in Spanish elderly.

Methods: We identified screening surveys, both published and unpublished, in Spanish populations, which fulfilled specific quality criteria and targeted prevalence of dementia in populations aged 70 years and above. Surveys covering 13 geographically different populations were
} 
selected (prevalence period: 1990-2008). Authors of original surveys provided methodological details of their studies through a systematic questionnaire and also raw age-specific data. Prevalence data were compared using direct adjustment and logistic regression.

Results: The reanalyzed study population (aged 70 year and above) was composed of Central and North-Eastern Spanish sub-populations obtained from 9 surveys and totaled 12,232 persons and I, I 94 cases of dementia (707 of Alzheimer's disease, 238 of vascular dementia). Results showed high variation in age- and sex-specific prevalence across studies. The reanalyzed prevalence of dementia was significantly higher in women; increased with age, particularly for Alzheimer's disease; and displayed a significant geographical variation among men. Prevalence was lowest in surveys reporting participation below $85 \%$, studies referred to urban-mixed populations and populations diagnosed by psychiatrists.

Conclusion: Prevalence of dementia and Alzheimer's disease in Central and North-Eastern Spain is higher in females, increases with age, and displays considerable geographic variation that may be method-related. People suffering from dementia and Alzheimer's disease in Spain may approach 600,000 and 400,000 respectively. However, existing studies may not be completely appropriate to infer prevalence of dementia and its subtypes in Spain until surveys in Southern Spain are conducted.

\section{Background}

Spain is one of the fastest aging societies in the world. According to the aging index, the proportion of the Spanish population aged 65 years and over (16.8\% in 2004) have doubled in the last 30 years ranking seventh among European countries http://eurostat.eu.europa.eu. Therefore, the burden of chronic neurodegenerative disorders, particularly dementia, is expected to grow exponentially.

Dementia screening surveys are population-based studies in which individuals that are screened positively through a cognitive or disability test, undergo a second phase of clinical assessment and diagnosis. The screening survey is the only methodologically sound research design capable of estimating dementia prevalence. It copes effectively with bias due to underdiagnosis of dementia in the community.

A review by the Spanish Epidemiological Study Group on Aging identified reports on age- and sex-specific prevalence of dementia from screening surveys referred to 6 populations conducted from 1990 to 2000 [1]. Crude dementia prevalence for elders aged 70 years or more ranged from $6.6 \%$ in Zaragoza to $17.2 \%$ in Pamplona. Prevalences of Alzheimer's disease (AD) in these surveys were $5.1 \%$ and $10.6 \%$, respectively. Vascular dementia (VD) was the second most frequent dementia subtype [1]. However, prevalence reported for Spanish populations by 2005 might be limited given the methodological differences across studies and the recent improvements in diagnostic criteria for infrequent dementia subtypes. In addition, the above-mentioned surveys focused on populations resident in the Northern half of the country, while Southern populations remain under-reported. The latter might be particularly important given the higher vascular mortality found in Southern Spain and the impact of vascular factors in the etiology of dementia [2].

This study sought to 1) estimate the prevalence of dementia in Spain reanalyzing the data from published and unpublished dementia prevalence screening surveys conducted to date, 2) identify study features related to the magnitude of dementia prevalence, and 3) compare the prevalence of dementia found in Spanish studies with that of selected European surveys.

\section{Methods}

In this report, we followed the recommendations of the Meta-analysis of Observational Studies in Epidemiology Group [3] for the purposes of identifying, appraising, synthesizing, and combining results from different surveys.

\section{Search strategy}

Studies on dementia prevalence in Spain were searched up to December 31, 2008 in PubMed, Indice Médico Español and Biblioteca Virtual en Salud. The following search words were used as MeSH or TIAB terms: "dementia," "prevalence," "door-to-door," "screening" and "Europe." Search was restricted to reports published in English and Spanish within the period 1985 through 2008. Search yielded 23 reports in English and 3 in Spanish. Upon authors' request, the Spanish Society of Neurology and the Spanish Society of Epidemiology provided information about one ongoing survey in Murcia (Eastern Spain).

\section{Studies selection}

Inclusion and exclusion criteria for survey selection approved by consensus by the Spanish Epidemiological 
Study Group on Aging were as follows: 1) survey incorporates an updated population census for a study population geographically defined by residence, 2) survey uses a screening instrument in the first phase of the study, 3 ) survey describes the diagnostic methods and the medical specialist in charge of diagnosis (e.g., geriatrician, neurologist, psychologist); 4) survey uses specific diagnostic criteria for dementia subtypes; and 5) survey includes no less than 20 dementia cases. Inclusion and exclusion criteria assured a minimum quality threshold.

Surveys potentially valid for analysis finished data collection by October 2008. The pool of potentially valid surveys included 1 pilot study [4], 14 published surveys [219], and 1 unpublished survey [20]. The target populations of these studies were: Pamplona, ZaragozaZARADEMP (two-time point measurements), NEDICES (three geographically distinct sub-populations in Central Spain), Toledo, Leganés, Gerona, La Selva del Camp, Turégano, Alcoi/Bañeres, Bidasoa and Munguialde, El Prat de Llobregat and Murcia.

Inclusion criteria were independently rated in each preselected survey by three co-authors (RB, JLB and JPC) through a questionnaire for data-collection, focusing on demographic, methodological, diagnostic, disabilityrelated and epidemiologic data to be requested from the authors of the selected surveys [5-11,13-21]. The NEDICES survey and studies in La Selva del Camp and Alcoi/Bañeres $[8,13,14]$ were excluded due to incomplete dataset. Authors of the ongoing study in Murcia [20] refrained from participating before the publication of their original data. Data from ZARADEMP first measurement was not provided [21]. The pilot study by BermejoPareja [4] and a study reporting 11 dementia cases aged $\geq$ 65 years [12] were excluded due to small sample size.

Nine studies covering 9 geographically different populations met inclusion criteria: Bidasoa, Munguialde, Gerona, Leganés, Pamplona, El Prat de Llobregat, Toledo, and Zaragoza, ZARADEMP one population each [5-7,9$11,15-17,19]$. Since some studies solely covered populations aged 70 years and over, the sub-populations used for reanalysis of selected studies comprised subjects over the age of 69 years, divided into 4, 5-year sex-specific strata, and two open-ended groups aged $\geq 70$ and $\geq 90$ years respectively.

The methodological characteristics of the selected surveys are presented in Additional File 1. The geographical locations of the surveys covered by reanalysis are shown in Figure 1. Prevalence years ranged from 1990 to 2005. The population size ranged from 524 in Leganés to 2,850 in ZARADEMP, and the number of cases went from 48 in Bidasoa to 214 in ZARADEMP. Data on the size of the

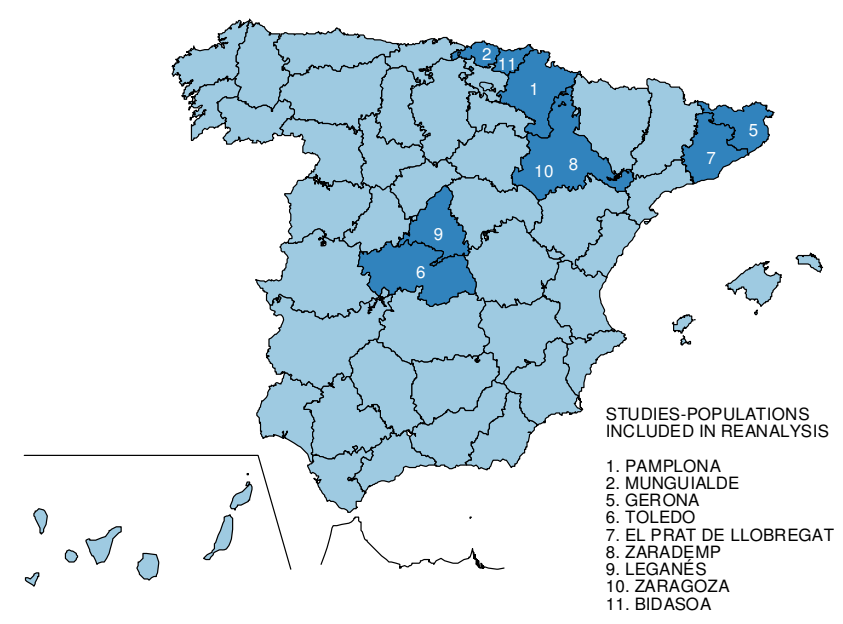

Figure I

Geographical location of reported and not reported, reanalyzed dementia prevalence surveys in Spain.

municipalities where the participants lived was obtained from the National Institute of Statistics http:// www.ine.es/. Municipalities were classified as rural $(<2,000$ inhabitants) and urban ( $\geq 10,000$ inhabitants). Urban metropolitan populations with a high proportion of immigrants, i.e., born outside the municipal boundaries, were denoted as suburban. An urban mixed category was used to identify former rural populations which had become urban in recent decades.

\section{Assessment of prevalence variation within Spanish reanalyzed surveys}

Age- and age- and sex-specific prevalence of dementia and major dementia subtypes were obtained for four 5-year age groups and an open $\geq 90$ years group. Crude prevalence proportions, as well as age- and sex-adjusted prevalence were calculated for the population aged $\geq 70$ years. We used the European standard population as the basis for adjustment (weights $0.43,0.29,0.14$ and 0.14 for 75 $79,80-84$ ad 85 and over years, respectively; http:// seer.cancer.gov/stdpopulations/stdpop.19ages.html.

For the purposes of assessing prevalence of dementia and its major subtypes, data from reanalyzed surveys were weighted against those of El Prat, which was taken as reference. El Prat was selected as reference due to its recency and large study size [17]. Unconditional logistic regression on grouped data controlling for age and sex was conducted. The prevalence variation in reanalyzed surveys by environment (rural, urban), diagnosing specialists (psychiatrist, neurologist, geriatricians) and percentage of participation of targeted population, was assessed using the same multivariate methods. Diagnosing specialist was 
considered a predictive factor due to the different diagnostic patterns among specialists with different backgrounds [19]. All analyses were carried out with Stata v. 8.0 (Stata Corporation, College Station, Texas).

\section{Results}

The combined population for reanalysis, hereafter Spanish-reanalyzed population, totaled 12,232 persons $(7,150,58 \%$ women $)$ and yielded 1,194 cases of dementia; 707 AD cases, and 238 cases of VD. The Spanish-reanalyzed population came from North and Central Spain and varied in terms of living environment. For instance, while the Zaragoza, Gerona, and Pamplona surveys focused on urban populations, those in Leganés and El Prat were suburban with a high proportion of immigrant population $(\sim 86 \%)$. Other sub-populations were less homogeneous, e.g., the Bidasoa and Toledo areas had a high proportion of immigrants and were both classified as urban-mixed. Detailed age- and sex-specific prevalence of dementia, as well as crude, and age- and sex-adjusted counts for participants aged $\geq 70$ years are shown in Additional File 2. Prevalence estimates of 9 and 8 sub-populations were available for AD and VD respectively. Age- and sex-specific prevalences are presented in Figure 2.

Dementia prevalence varied substantially across surveys in age-specific groups: up to four-fold increase among the oldest group (Figure 2). Differences in crude prevalence for participants aged $\geq 70$ years were consistent across gender and age groups (Figures 2), ranging from 3.5\% in Bidasoa to $17.2 \%$ in Pamplona. Age- and sex-adjusted prevalence in the same age-group ranged from $3.2 \%$ in Bidasoa to $12.3 \%$ in Gerona, while the corresponding figures in the El Prat survey were intermediate (9.6 and $9.3 \%)$.

In the case of $\mathrm{AD}$ both sexes, age- and sex-adjusted prevalence at age $\geq 70$ years, ranged from $2.6 \%$ in ZARADEMP to $7.7 \%$ in El Prat, and in the case of VD, from $1.2 \%$ in El Prat and ZARADEMP to $5.1 \%$ in Gerona.

Insofar as Lewy body dementia (LBD) and frontotemporal dementia (FTD) were concerned, little information was available in the Spanish-reanalyzed population. Crude LBD prevalence at $\geq 70$ years was $2.0 \%$ in El Prat and Bidasoa and $0.8 \%$, including parkinsonism with dementia in Muguialde. The corresponding values for FTD were $2.0 \%$ ( 2 cases) in El Prat, $0.1 \%$ in Munguialde (1 case).

The common age- and sex-specific pattern for all surveys can be summarized as follows: 1) an increase in dementia prevalence with age across sex groups, higher for AD than for VD; and, 2) a higher prevalence of dementia among women (Figure 2).
The logistic regression results (Additional File 3) pointed to a significantly higher prevalence of dementia in women OR 1.45 (95\%CI 1.27 - 1.66), increasing with age and differing by place of residence. The prevalence of dementia in both sexes in El Prat proved significantly higher than that in some of the reanalyzed surveys (ZARADEMP, Zaragoza and Bidasoa). The overall OR variation between Gerona and Bidasoa was five-fold. Alzheimer's disease prevalences of Spanish-reanalyzed sub-populations referred to El Prat showed significant departures in two surveys: Bidasoa, OR = 0.42 (95\% CI 0.32 - 0.55), and Pamplona, OR $=1.35$ (95\% CI $1.03-1.77)$. For VD, with few populations available for comparison, differences were significant when Gerona, OR = $5.00(95 \%$ CI 3.06 - 8.16), and Toledo, OR = 2.05 (95\% CI 1.12 - 3.73), were considered. ORs for the oldest age group showed a seven-fold and eighteen-fold increase for VD and AD respectively.

Results of reanalysis by type of diagnosing specialist, living environment and level of participation are reported in Additional File 4. Lower prevalence of AD, VD and overall dementia were reported by surveys carried out by psychiatrists compared to neurologists and geriatricians. Similar prevalence of $\mathrm{AD}$ and higher prevalence of VD among men were found when diagnosis was conducted by geriatricians as opposed to neurologists. Reanalyzed suburban populations of both sexes had a lower VD prevalence, and higher prevalence of AD than urban sub-populations did. Significantly lower prevalences of dementia, AD and VD were systematically found when participation was below $<85 \%$. The only unreported survey analyzed (Bidasoa) showed lower dementia prevalence when weighted against published surveys, OR $=0.32$ (95\% CI 0.24 0.44).

\section{Discussion}

The present study is a comprehensive, comparative approach to the prevalence of dementia and its subtypes in Spanish populations. The most relevant findings can be summarized as follows: 1) dementia prevalence was highly variable across reanalyzed sub-populations, 2) dementia prevalence attributable to $\mathrm{AD}$ is higher among women; 3) dementia prevalence varied as a result of the composition of the diagnostic team (neurologist, psychiatrist, geriatrician, psychologist), the municipality category (urban, suburban, urban-mixed) and the percentage of participation of originally screened participants. Inconsistent results across studies may be whether due to the diverse designs used across studies or due to actual prevalence variations caused by changes in incidence or survival. Since there are limitations due to study power, these results should be taken cautiously.

Although the present study incorporated three surveys not previously reanalyzed [1], it lacked information on the 

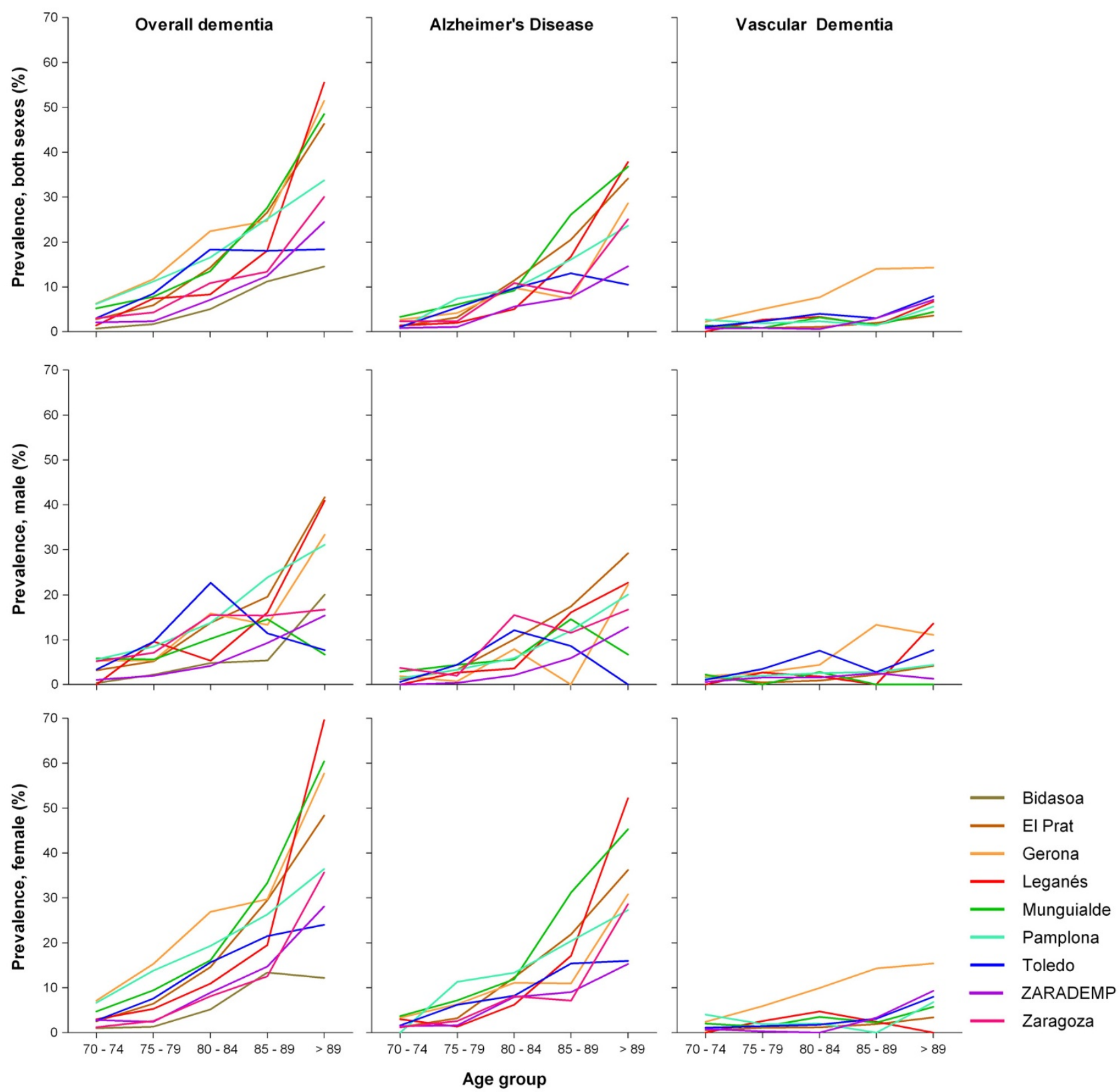

Figure 2

Age-specific prevalence of dementia, Alzheimer's disease and vascular dementia in reanalyzed Spanish populations by gender.

prevalence of dementia in Southern Spain. This may be particularly misleading given that cardiovascular and cerebrovascular mortality is reportedly higher in Southern Spain $[2,22]$. Moreover, prevalence of vascular risk factors (low folic acid intake, hypercholesterolemia, arterial hypertension, diabetes mellitus and smoking habit) is also higher in this region $[23,24]$. Unfortunately, surveys conducted in areas where a high mortality due to stroke have been reported (South-West Spain (Alcoi/Bañeres and Murcia) [22-25] could not enter the analysis.

Since variation in screening instruments and participation level were modest (range 62\%-92.4\%), it could be argued that differences in prevalence of dementia were largely 
caused by inconsistent methods across surveys. Leganés study [10] implemented sequential screening methods that may have induced losses at follow up. On the other hand, Leganés and Toledo studies $[9,10]$ may have shown an artifactually high sensitivity resulting from the clinical evaluation of a large group of negatively screened participants. However, these shortcomings may have not been highly detrimental to the internal validity of these studies since the prevalence reported for Leganés and Toledo fell within the range of variation of other surveys (see Figure 2).

Regarding specialist-specific diagnostic patterns, although there is some evidence suggesting that psychiatrist approach dementia differently as opposed to other medical professionals [26], our findings may be considered artifactual. First, there is only one study involving a single geriatrician, and he happened to be assisted by a psychiatrist [9]. Therefore specific diagnostic patterns for geriatricians and psychiatrists can not be clearly disentangled. Second, the seemingly high likelihood of dementia diagnosis associated to geriatricians was limited to vascular dementia (Additional File 4). Third, Toledo is located in the mid-South of the country were cardiovascular mortality has been found to be higher [2], which suggests further that differences found in Toledo may not be solely attributable to the background of the diagnosticians. In summary, it suffices to say that variation in the background of diagnostic teams across studies may have induced some degree of heterogeneity to dementia prevalence. However, the limited number of studies and the various compositions of diagnostic teams preclude any specific conclusion as regards to univocal relationships between a given specialist and over- or under-diagnostic trends.
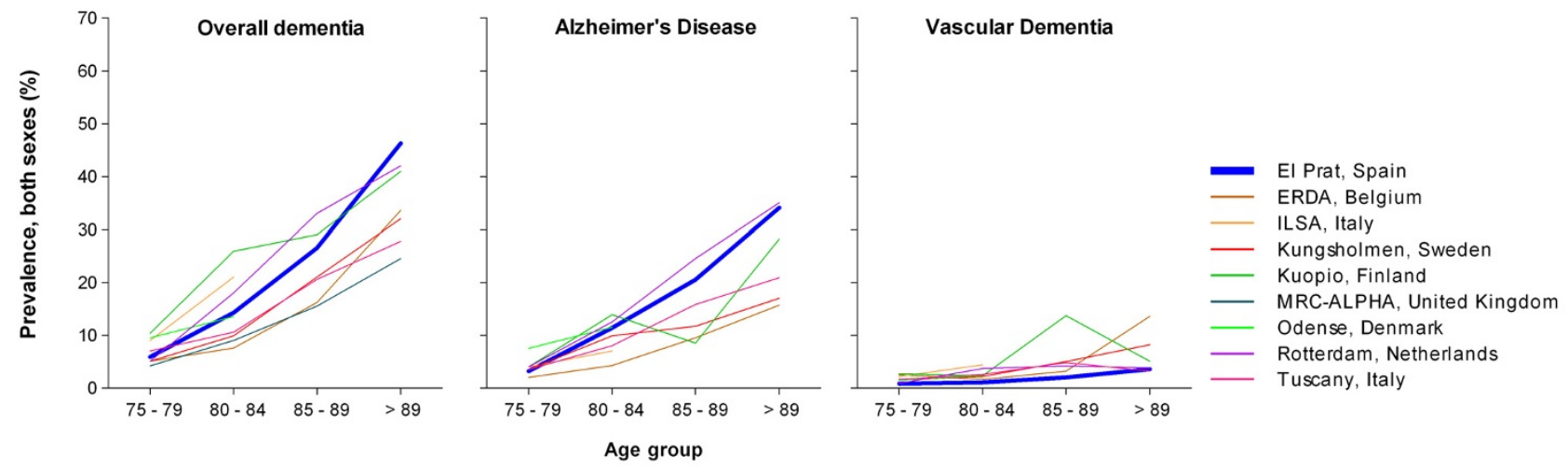

Figure 3

Age-specific prevalence of dementia, Alzheimer's disease and vascular dementia in European and El Prat populations, data for both sexes. 
conducted in Girona, which offered 23.2 and 10.8 per 1000 person-years for dementia and $\mathrm{AD}$, respectively, for those aged 75 years or more [27]. Regarding disease duration and survival of dementia subtypes, while differences exist in terms of higher mean duration of $\mathrm{AD}$, lower mean duration of FTD (6.2 versus 4.2 mean years [40]), and shorter duration of dementia with clinical vascular components [41], it seems that the impact of these factors on prevalence is still difficult to estimate. Most studies show a slower increase of age-specific prevalence of VD with age as opposed to age-specific prevalence of $\mathrm{AD}$, which may be attributable to shorter survival. Methodological aspects affecting under-diagnosis in Central Spain surveys have been pin-pointed by Bermejo et al. [42] and have been observed here, particularly those related to non-participation and screening validation. Such problems might account for the lower dementia prevalence of the unreported survey.

\section{Conclusion}

Prevalence of dementia and AD in Central and NorthEastern Spain is higher in females, increases with age, and displays considerable geographic variation that may be method-related. Prevalence figures were similar or lower than those found in Western Europe. The present reanalysis indicated that some 600,000 and 400,000 people have dementia and AD in Spain, respectively. However, extrapolation should be taken cautiously until surveys conducted in Southern Spain are available.

\section{List of abbreviations}

AD: Alzheimer's disease; VD: vascular dementia; LBD: Lewy body dementia; FTD: Fronto-temporal dementia. OR: Odds ratio; CI: Confidence Interval.

\section{Competing interests}

The authors declare that they have no competing interests.

\section{Authors' contributions}

JLB, JPC and RB participated in designing the reanalysis methods, and drafted the first manuscript. JLB and JVO participated in day-to-day coordination, managed the database, performed most of the statistical analysis, and contributed to later versions of the manuscript. JPC, FBP, ARL and most other authors participated in study design, data-collection, and in a critical review of the manuscript. JPC (study coordinator), PM, and FBP conceived the study. All authors read and approved the final manuscript.

\section{Additional material}

\author{
Additional file 1 \\ Supplemental Table S1. Methodological aspects of selected, door-to-door \\ prevalence surveys of dementia in Spanish populations. \\ Click here for file \\ [http://www.biomedcentral.com/content/supplementary/1471- \\ 2377-9-55-S1.DOC]
}

\section{Additional file 2}

Supplemental Table S2. Age and sex-specific counts for aged $\geq 70$ years, crude, and age-adjusted or age-and sex-adjusted prevalence of dementia, Alzheimer's disease and vascular dementia in reanalyzed Spanish surveys. Click here for file

[http://www.biomedcentral.com/content/supplementary/14712377-9-55-S2.DOC]

\section{Additional file 3}

Supplemental Table S3. Prevalence OR of dementia, Alzheimer's disease and vascular dementia with $95 \% \mathrm{CI}$, adjusted for age and age- and sex (reference: El Prat survey).

Click here for file

[http://www.biomedcentral.com/content/supplementary/1471-

2377-9-55-S3.DOC]

\section{Additional file 4}

Supplemental Table S4. Age- and sex-adjusted prevalence odd ratios plus 95\% confidence interval of dementia, Alzheimer's disease and vascular dementia for selected factors among $\geq 70$ participants.

Click here for file

[http://www.biomedcentral.com/content/supplementary/14712377-9-55-S4.DOC]

\section{Acknowledgements}

tThis article is dedicated to the Memory of Dr. José María Manubens. The authors would like to thank Michael Benedict for his help with the English version of the manuscript. Financial aid was obtained from the Spanish RECSP C03-09, CIEN C03-06 and CIBERNED networks, and from the Pfizer Foundation in particular. Ethical evaluation was not required for this reanalysis. The authors would like to thank the Spanish epidemiological study group on ageing by support for assessing quality of survey data, and when deemed valuable, extracting and providing information from surveys and administrative support:

-National Center for Epidemiology. Carlos III Institute of Public Health: Javier Almazán, José Luis del Barrio, Raquel Boix, Fuencisla Avellanal, Pablo Martínez, María José Medrano, Jesús de PedroCuesta, Francisco Javier Virués and Ignacio Mahillo. Madrid.

-Alcoy (Alcoi): Alicante: Manuel Girón, Jordi MatíasGuiu, José Manuel Moltó. Neurology Unit. Miguel Hernández University. General University Teaching Hospital. Alicante.

-Barcelona: El Prat de Llobregat: Jordi Gascón, Ramón Reñé. Dementia Diagnosis and Treatment Unit. Neurology Department. Bellvitge University Teaching Hospital. Barcelona. 
-EPICARDIAN Project: Margarita Alonso, Cristina Fernández, Rafael Gabriel. Clinical Epidemiology Research Unit. La Paz University Teaching Hospital. Madrid

-Gerona: Josep Garré Olmo, Secundino López Pousa, Jordi Llinàs Reglà, Joan Vilalta Franch. Dementia Unit. Santa Caterina Hospital. Gerona.

-Granada: Jorge Cervilla. Department of Psychiatry, Granada University.

-Guipúzcoa: Ana de Arce, Alberto Bergareche. Neurology Department. Donostia Hospital, BidasoaHondarribia Hospital. Guipúzcoa.

-Economics and Geography Institute. Scientific Research Board: Gloria Mayoralas, Fermina Rojo. Madrid.

-Leganés Project: Angel Otero, Angel Rodríguez. Madrid Autonomous University,

Department of Preventive Medicine. Madrid Regional Health Authority. Madrid.

-Munguialde Project. Manuel Fernández Martínez: Servicio de Neurología. Hospital de Cruces. Centro médico de día OROITU GetxoVizcaya; Susana Pérez de las Heras Centro de Salud Llodio. Centro médico de día OROITUGetxoVizcaya; Aitziber Mandaluniz Lekumberri: Fundacion Jose Etxealai, MunguiaVizcaya; María Gordejuela Menocal: Fundacion Jose Etxealai, MunguiaVizcaya, Jessica Castro Flores: Servicio de Neurología. Hospital de Cruces Vizcaya y Juan José Zarranz Imirizaldu: Servicio de Neurología. Hospital de CrucesVizcaya.

-NEDICES Project: Julián Benito, Félix BermejoPareja, Jaime Díaz, Rafael Gabriel, Candelas Gómez Mateos, Javier Guzmán, José Manuel Morales, Fernando Sánchez, Patricia Vale, Saturio Vega. Neurology Department. 12 de Octubre University Teaching Hospital. Madrid.

-Pamplona: José María Manubens.† Neurology Unit. Virgen del Camino Hospital. Pamplona.

-Pontevedra: Manuel Seijo Martínez, Angel Aneiros, Neurology Service, Hospital do Salnés, and Ramón Suarez, Eugenio Torres. Primary Care Unit, Isla de Arosa, Pontevedra.

-Santiago de Compostela. Corunna (La Coruña): Carmen García, Raimundo Mateos, Ramón Ramos. Psychiatry Department, University of Santiago de Compostela (USC) and Psychogeriatrics Unit. Santiago de Compostela University Teaching Hospital.

-Segovia: Jacinto Duarte, Amelia Mendoza, Fernanda Rodríguez. Neurology Unit. Segovia General Hospital.

-Toledo: Francisco José García. Geriatrics Unit. Virgen del Valle Geriatric Hospital. Toledo.

-Zaragoza: Antonio Lobo, Pedro Saz. Department of Medicine and Psychiatry. Zaragoza University.

\section{References}

I. Del Barrio JL, de Pedro-Cuesta J, Boix R, Acosta J, Bergareche A, Bermejo-Pareja F, Gabriel R, et al.: Dementia, Stroke and Parkinson's Disease in Spanish Populations: A Review of Door-toDoor Prevalence Surveys. Neuroepidemiology 2005, 24: I79-I 88.

2. European Commission: Health statistics: Atlas on mortality in the European Union. Luxemburg: Office for official publications of the European communities; 2009:128-129.
3. Stroup DF, Berlin JA, Morton SC, Olkin I, Williamson GD, Rennie D, et al: Meta-analysis of observational studies in epidemiology. JAMA 2000, 283:2008-20I2.

4. Bermejo-Pareja F, Vega S, Morales J, Díaz J, López L, Parra D, et al: Prevalence of stroke in two samples (rural and urban) of old people in Spain. A pilot door-to-door study carried out by health professionals. Neurología 1997, I2:157-16I.

5. Lobo A, Saz P, Marcos G, Día JL, de la Cámara C: The prevalence of dementia and depression in the elderly community in a southern European population. The Zaragoza Study. Arch Gen Psychiatry 1995, 52:497-506.

6. Lobo A, Launer LJ, Fratiglioni L, Andersen K, Di Carlo A, Breteler $M M B$, et al:: Prevalence of dementia and major subtypes in Europe: a collaborative study of population-based cohorts. Neurology 2000, 54(Suppl 5):S4-S9.

7. Manubens JM, Martínez-Lage JM, Lacruz F, Muruzabal J, Larumbe R, Guarch C, Urrutia T, Sarrasqueta P, Martínez-Lage P, Rocca WA: Prevalence of Alzheimer's disease and Other Dementing Disorders in Pamplona, Spain. Neuroepidemiol I995, I4:I55-64.

8. Morales JM, Bermejo FP, Benito-Leon J, Rivera-Navarro J, Trincado R, Gabriel SR, Vega S, NEDICES Study Group: Methods and demographic findings of the baseline survey of the NEDICES cohort: a door-to-door survey of neurological disorders in three communities from Central Spain. Public Health 2004, I 1 8:426-433.

9. García FJ, Sánchez MA, Pérez A, Martín E, Marsal C, Rodríguez G, et al.: Prevalencia de demencia y de sus subtipos principales en sujetos mayores de 65 años: efecto de la educación y ocupación. Estudio Toledo. Med Clin 200 I, I I 6:40 I-407.

10. Zunzunegui MV, del Ser T, Rodríguez-Laso A, García de Yébenes MJ, Domingo J, et al.: Demencia no detectada y utilización de los servicios sanitarios implicaciones para la atención primaria. Aten Primaria 2003, 3 I:581-586.

II. Vilalta-Franch J, López-Pousa S, Llinás-Reglá J: Prevalencia de demencias en una zona rural. Estudio de Girona. Rev Neurol 2000, 30:1026-1032.

12. Coria F, Gómez-de-Caso JA, Mínguez L, Rodríguez-Artalejo F, Claveía LE: Prevalence of age-associated memory impairment and dementia in a rural community. I Neurol Neurosurg Psychiatry 1993, 56:973-976.

13. Pi J, Olivé JM, Roca J, Masana L: Prevalence of Dementia in a Semi-Rural Population of Catalunya, Spain. Neuroepidemiol 1996, | 5:33-4|.

14. Matías-Guiu J, Viñets C, Falip R, López-Arlandis J, Oltra A, Canet T: Epidemiología descriptiva del accidente isquémico transitorio: estudio en Muro d'Alcoi. Rev Neurol 1995, 23:422-424.

15. Bergareche A, De-la-Puente E, López-de-Munain A, Sarasqueta C, DeArce A, Poza J], Martí-Massó JF: Prevalence of Parkinson's disease and other types of Parkinsonism. A door-to-door survey in Bidasoa, Spain. J Neurol 2004, 25 I:340-345.

16. Bergareche A, De la Puente E, López de Munain A, Sarasqueta C, De Arce A, Poza JJ, Martí-Massó JF: Prevalence of essential tremor: a door-to-door survey in Bidasoa, Spain. Neuroepidemiology 2001, 20:125-128.

17. Gascón-Bayarri J, Reñé R, Del Barrio JL, De Pedro-Cuesta J, Ramón JM, Manubens JM, et al.: Prevalence of dementia subtypes in EI Prat de Llobregat, Catalonia, Spain: The PRATICON Study. Neuroepidemiology 2007, 28:224-234.

18. Fernández M, Castro J, Pérez S, Mandaluniz A, Gordejuela M, Zarranz J): Prevalencia de demencia en Mungialde (Vizcaya). Neurología 2006, 2 1:551-577.

19. Fernández M, Castro J, Pérez S, Mandaluniz A, Gordejuela M, Zarranz Jj: Risk factors for dementia in the epidemiological study of Munguialde County (Basque Country-Spain). BMC Neurology 2008, 8:39.

20. Gavrilla D, Antúnez C, Tormo MJ, Navarro G, Parrilla JM, García R, et al:: Prevalencia de demencia y deterioro cognitivo leve en la región de Murcia. Estudio ARIADNA [Abstract]. Gac Sanit 2005, I9(Supl I):

21. Lobo A, Saz P, Marcos G, Dia JL, De-la-Camara C, Ventura T, Montañes JA, Lobo-Escolar A, Aznar S, ZARADEMP Workgroup: Prevalence of dementia in a southern European population in two different time periods: The ZARADEMP Project. Acta Psychiatr Scand 2007, I 1 6:299-307.

22. Barrado MJ, de Pedro-Cuesta J, Almazán J: Stroke mortality in Spain 1901-I984. Neuroepidemiology 1993, I 2: I48-I57. 
23. Medrano MJ, Sierra MJ, Almazan J, Olalla MT, López-Abente G: The association of dietary folate, $B_{12}$ and $B_{6}$ with cardiovascular mortality in Spain. An ecological analysis. Am J Public Health 2000, 90:1636-1638.

24. Del Barrio J, Medrano M, Arce A, Bergareche A, Bermejo F, Diaz J, et al.: Prevalence of vascular risk factors among Spanish populations aged $\mathbf{7 0}$ years and over, as reported in door-to-door studies on neurological diseases. Neurologia 2007, 22: I 38-I 46.

25. Lopez-Abente G, Pollán, Escolar A, Errezola M, Abraira V: Atlas de mortalidad por cancer y otras causas en España, 1978-1992. Madrid: Instituto de Salud Carlos III 200I:I54-I55.

26. Wolff $L E$, Woods JP, Reid J: Do general practitioners and old age psychiatrists differ in their attitudes to dementia? Int J Geriatr Psychiatry 1995, 10:63-69.

27. López-Pousa S, Vilalta-Franch J, Llinas-Regla J, Garré-Olmo J, Roman GC: Incidence of dementia in a rural community in Spain: the Girona cohort study. Neuroepidemiol 2004, 23:170-177.

28. Roman GC: Defining dementia: Clinical criteria for the diagnosis of vascular dementia. Acta Neurol Scand 2002, 178(Suppl I):6-9.

29. Verhery FR, Lodder J, Rozendall N, Jolles J: Comparison of seven sets of criteria used for the diagnosis of vascular dementia. Neuroepidemiol 1996, I 5:166-I72.

30. Weterling T, Kanitz RD, Borgis KJ: Comparision of different diagnostic criteria used for vascular dementia (ADDT, DSM-IV ICD-1 0, NINDS-AIREN). Stroke 1996, 27:30-36.

31. Roelands M, Wostyn P, Dom H, Baro F: The prevalence of dementia in Belgium: A population-based door-to-door survey in a rural community. Neuroepidemiol 1994, 13:155-161.

32. Fratiglioni L, Grut M, Forsell Y, Viitanen M, Grafström M, Holmén K, Ericsson K, Bäckman L, Ahlbom A, Winblad B: Prevalence of Alzheimer's disease and other dementias in an elderly urban population: Relationship with age, sex and education. Neurology |99|, 4 I: |886-|892.

33. Breteler MMB, Ouweland FA Van den, Grobbee DE, Hofman A: A Community-Based Study of Dementia: the Rotterdam Elderly Study. Neuroepidemiology 1992, I I (SuppI I):23-28.

34. Maggi S, Zucchetto M, Grigoletto F, Baldereschi M, Candelise L, Scarpini E, Scarlato G, Amaducci L: The Italian Longitudinal Study on Aging (ILSA): design and methods. Aging Clin Exp Res 1994, 6:464-473.

35. Saunders PA, Copeland JRM, Dewey ME, Gilmore C, Larkin BA, Phaterpekar H, Scott A: The prevalence of Dementia, Depression and Neurosis in Later Life: the Liverpool MRC-ALPHA Study. Int J Epidemiol 1993, 22:838-847.

36. Tognoni G, Ceravolo R, Nucciarone B, Bianchi F, Dell'Agnello G, Ghicopulos I, Siciliano G, Murri L: From mild cognitive impairment to dementia: a prevalence study in a district of Tuscany, Italy. Acta Neurol Scand 2005, I I 2:65-7I.

37. Rahkonen $T$, Eloniemi-Sulkava U, Rissanen $S$, Vatanen A, Viramo $P$ Sulkava R: Dementia with Lewy bodies according to the consensus criteria in a general population aged 75 years or older. J Neurol Neurosurg Psychiatry 2003, 74:720-724.

38. Stevens T, Livingston G, Kitchen G, Manela M, Walker Z, Katona C Islington study of dementia subtypes in the community. $\mathrm{Br}$ Psychiatry 2002, 180:270-276.

39. Rothman KJ, Greenland S: Measures of disease frequency. In Modern Epidemiology 2nd edition. Edited by: Rothman KJ, Greenland S. Philadelphia: Lippincott-Raven Publishers; 1998:42-45.

40. Rascovsky K, Salmon DP, Lipton AM, Leverenz JB, DeCArli C, Jagust W], et al: Rate of progression differs in frontotemporal dementia and Alzheimer disease. Neurology 2005, 65:397-403.

41. Sheng B, Cheng LF, Law CB, Li HL, Yeung KM, Lau KK: Coexisting cerebral infarction in Alzheimer's disease is associated with fast dementia rogression. J Am Geriatr Soc 2007, 55:918-922.

42. Bermejo F, Gabriel R, Vega S, Morales JM, Rocca W, Anderson D: Problems and issues with door-to-door, two-phase surveys: an illustration from central Spain. Neuroepidemiol 200I, 20:225-231.

\section{Pre-publication history}

The pre-publication history for this paper can be accessed here: http://www.biomedcentral.com/1471-2377/9/55/prepub
Publish with Biomed Central and every scientist can read your work free of charge

"BioMed Central will be the most significant development for disseminating the results of biomedical research in our lifetime. "

Sir Paul Nurse, Cancer Research UK

Your research papers will be:

- available free of charge to the entire biomedical community

- peer reviewed and published immediately upon acceptance

- cited in PubMed and archived on PubMed Central

- yours - you keep the copyright
BioMedcentral 